\title{
PERSEPSI DAN SIKAP PESERTA DIDIK SMAN TERHADAP FUNGSI KAWASAN EKOSISTEM MANGROVE DALAM MENDUKUNG EDUEKOWISATA
}

\section{PERCEPTION AND ATTITUDES OF STUDENTS ON THE FUNCTION OF THE MANGROVE ECOSYSTEM AREA IN SUPPORTING EDUECOTOURISM}

\author{
Hadi Purwanto ${ }^{1)}$, Agusminarti ${ }^{2)}$, Fauzan Azim ${ }^{3)}$, Supriyatno ${ }^{4)}$ \\ 1), 2), 3), 4) Universitas Muhammadiyah Riau \\ hadipurwanto@umri.ac.id
}

diterima: 1 September 2020; dipublikasi: 31 Oktober 2020

DOI: 10.32528/bioma.v5i2.4007

\begin{abstract}
ABSTRAK
Penelitian ini bertujuan untuk mengetahui persepsi dan sikap peserta didik di SMA Negeri 2 dan 3 Sungai Apit terhadap fungsi kawasan ekosistem mangrove dalam mendukung eduekowisata. Penelitian dilaksanakan pada bulan Mei hingga Agustus 2020. Penelitian ini adalah penelitian deskriptif dan pengumpulan data menggunakan angket, dokumentasi, wawancara dan observasi. Sampel dalam penelitian ini sebanyak 66 peserta didik. Dalam penelitian ini terdapat dua variabel yaitu persepsi dan sikap dengan beberapa indikator. Variabel persepsi \{fungsi hutan mangrove secara fisik (77,94\%), fungsi hutan mangrove secara biologi $(80,15 \%)$, fungsi hutan mangrove secara ekonomi $(83,24 \%)$, fungsi hutan mangrove secara eduekowisata $(81,74 \%)$ \} dan variable sikap \{rasa ingin tahu $(83,62 \%)$, komunikasi $(88,26 \%)$, peduli lingkungan $(86,62 \%)$, peduli sosial $(87,88 \%)$, tanggung jawab $(87,69 \%)\}$. Dari kedua variable dan sembilan indikator sudah dapat mengambarkan bagaimana persepsi $81 \%$ (sedang) dan sikap $86,81 \%$ (tinggi) peserta didik di SMA Negeri Sungai Apit.
\end{abstract}

Kata kunci: Persepsi, Sikap, Ekosistem Mangrove, Eduekowisata

\begin{abstract}
This study aims to determine the extent to which students' perceptions and attitudes at SMA Negeri 2 and 3 Sungai Apit on the function of the mangrove ecosystem in supporting eduecotourism. The research was conducted from May to July 2020. This research is a descriptive study and data collection using questionnaires, documentation, interviews and observations. The sample in this study were 66 students. In this study, there are two variables, namely perceptions and attitudes, with several indicators. Perception variable $(77.94 \%)$, biological function of mangrove forest $(80.15 \%)$, economic function of mangrove forest $(83.24 \%)$, the function in eduecotourism $(81.74 \%)$ \} and attitude variables \{curiosity $(83.62 \%)$, communication $(88.26 \%)$, environmental care $(86.62 \%)$, social care $(87.88 \%)$, responsibility $(87.69 \%)\}$. So, it can describe how the perceptions of $81 \%$ (moderate) and $86.81 \%$ (high) attitudes of students in Sungai Apit State Senior High School.
\end{abstract}

Keywords: Perceptions, Attitudes, Mangrove Ecosystems, Eduecotourism 


\section{PENDAHULUAN}

Menurut Undang-Undang Sistem Pendidikan Nasional Nomor 20 Tahun 2003 Bab II pasal 3, mengemukakan bahwa: Pendidikan nasional berfungsi mengembangkan kemampuan dan membentuk watak serta peradaban bangsa, bertujuan untuk berkembangnya potensi peserta didik agar menjadi manusia yang beriman dan bertakwa kepada Tuhan Yang Maha Esa, berakhlak mulia, sehat, berilmu, cakap, kreatif, mandiri, dan menjadi warga negara yang demokratis seta bertanggung jawab. Dalam hal ini guru merupakan komponen yang sangat penting guna terwujudnya tujuan pendidikan. Perkembangan zaman telah menuntut guru untuk lebih berkembang dan kreatif lagi dalam melakukan proses pembelajaran, misalnya dengan menggunakan berbagai macam sumber belajar (Fajar, 2016).

Salah satu sumber belajar di luar adalah ekosistem hutan mangrove. Wilayah pesisir Indonesia memilki luas dan potensi ekosistem mangrove yang cukup besar. Dari sekitar 15.900 juta ha hutan mangrove yang terdapat di dunia, 27\% atau 4.293 juta ha berada di Indonesia.Kabupaten siak merupakan salah satu Kabupaten yang berada didaerah Provinsi Riau yang ibukota nya adalah Siak Sri Inderapura Secara geografis Kabupaten Siak terletak pada koordinat 1016'30"- 00 20'49”' Lintang Utara dan 10054' 21 ” $-102^{\circ} 10^{\prime} 59$ ” Bujur Timur. Secara fisik geografis memiliki kawasan pesisir pantai yang berhampiran dengan sejumlah negara tetangga dan masuk kedalam daerah segitiga pertumbuhan (growth triangle) Indonesia - Malaysia - Singapura (Rohman, 2015)

Selain itu siak juga memiliki pesisir pantai di sepanjang selat panjang dan di selimuti dengan hijaunya hutan mangrove yang luasnya 1415.693 ha sepanjang pesisir dan terdapat beberapa dimanfaatkan untuk keperluan lain seperti kayu bakar, bahan industri, dan kebutuhan lainya serta spot wisata mangrove dan hutan mangrove alami. hutan mangrove merupakan komunitas vegetasi pantai tropis yang didominasi oleh beberapa jenis pohon yang mampu tumbuh dan berkembang pada daerah pasang surut pantai berlumpur. Hutan mangrove umumnya tumbuh pada daerah intertidal dengan genangan air secara berkala dan menerima pasokan air tawar yang cukup.

Ekosistem hutan mangrove bersifat khas, baik karena adanya pelumpuran yang mengakibatkan kurangnya aerasi tanah, salinitas tanahnya yang tinggi, serta mengalami daur penggenangan oleh pasang-surut air laut. Hanya sedikit jenis tumbuhan yang 
bertahan hidup di tempat semacam ini, dan jenis-jenis ini kebanyakan bersifat khas hutan bakau karena telah melewati proses adaptasi dan evolusi.

Rohman (2015) menyatakan bahwa:

Dewasa ini, keadaan hutan mangrove di Indonesia masih banyak mengalami kerusakan. Faktor penyebab kerusakan mangrove antara lain, Potensi pembangunan yang terdapat di wilayah pesisir dan laut mengakibatkan terjadinya abrasi di sekitar hutan mangrove, aktivitas masyarakat yang membuka hutan mangrove untuk dijadikan ladang padi, dan kegiatan industry.

Potensi pembangunan sebagai ekowisata mangrove yang perlu diperhatikan adalah kondisi lingkungan sebagai tempat interaksinya manusia dengan makhluk hidup lainnya maupun makhluk yang tidak hidup. Pada hakekatnya ekowisata yang melestarikan dan memanfaatkan alam dan budaya masyarakat, jauh lebih ketat dibanding dengan hanya keberlanjutan. Pembangunan ekowisata berwawasan lingkunganjauh lebih terjamin hasilnya dalam melestarikan alam dibanding dengan keberlanjutan pembangunan. Sebab ekowisata tidak melakukan eksploitasi alam, tetapi hanya menggunakan jasa alam dan masyarakat untuk memenuhi kebutuhan pengetahuan, fisik/ dan psikologis wisatawan. Bahkan dalam berbagai aspek ekowisata merupakan bentuk wisata yang mengarah ke metatourism. Ekowisata bukan menjual destinasi tetapi menjual filosofi antara lain Dari aspek inilah ekowisata tidak akan mengenal kejenuhan pasar (Eko, 2006)

Dari berbagai hal tersebut perlu upaya yang dapat dilakukan dalam mengantisipasi masalah ini, tentu yang paling penting untuk dilakukan adalah menumbuhkan kesadaran manusia itu sendiri akan pentingnya menjaga kelestarian ekosistem hutan mangrove. Apabila kesadaran itu telah terbentuk maka usaha apapun yang bertujuan untuk memperbaiki dan menjaga ekosistem hutan mangrove akan lebih mudah tercapai. Untuk ini diperlukan pandangan-pandangan atau persepsi dan sikap peserta didik lebih digalakkan dalam menunjang kegiatan-kegiatan yang ada dilingkungan dalam hal ini pelestarian ekosistem hutan mangrove.

Kesadaran akan pentingnya pandangan atau persepsi dan sikap positif terhadap lingkungan pesisir tidak datang dengan sendirinya, melainkan harus ditumbuhkan dan dibina melalui pendidikan secara formal, non formal maupun informal. Dari pernyataan diatas terkandung makna yang dalam yaitu bahwa dengan pendidikan diharapkan akan 
tercipta rasa tanggung jawab dan cinta terhadap tanah air, yang pada akhirnya akan menumbuhkan pandangan-pandangan atau persepsi serta sikap yang positif terhadap lingkungan alam ini khususnya dalam menjaga ekosistem hutan mangrove sumber daya pesisir agar tetap lestari.

Dari permasalahan diatas terkandung makna yang dalam yaitu bahwa dengan pendidikan diharapkan akan tercipta rasa tanggung jawab dan cinta terhadap tanah air, yang pada akhirnya akan menumbuhkan pandangan-pandangan atau persepsi serta sikap peserta didik SMA Negeri disungai apit terhadap fungsi kawasan ekosistem mangrove dalam mendukung eduekowisata

Tujuan dari penelitian ini adalah untuk memberi arahan serta informasi terhadap guru agar mampu memanfaatkan kawasan ekosistem mangrove sebagai sumber belajar serta meningkatkan kompetensi dalam pembelajaran outdoor learning dan bagi peserta didik dapat mengetahui bahwa pentingnya melindungi dan menjaga lingkungan wilayah pesisir serta sebagai aktifitas proses pembelajaran di luar sekolah untuk wawasan.

\section{METODE}

Penelitian dilaksanakan di SMA Negeri 2 Sungai Apit dan SMA Negeri 3 Sungai Apit, Kec. Sungai Apit, Kab. Siak pada bulan Mei sampai bulan Agustus 2020, merupakan sekolah yang berdampingan langsung dengan kawasan ekosistem mangrove. Pada tahap awal peneliti membagikan angket persepsi dan sikap pada peserta didik yang dijadikan sebagai sampel penelitian dimana berjumlah 66 orang. Pengumpulan data dilakukan pada 4 kelas, setelah peneliti membagikan angket dan memberikan tata cara pengisian angket, selanjutnya pengisian angket peneliti memilih 8 peserta didik untuk wawancara dimana tujuannya untuk memperoleh informasi langsung dari peserta didik.

Metode pengambilan sampel pada penelitian ini dengan menggunakan survei, selanjutnya pengumpulan data menggunakan instrumen lembar observasi, angket, wawancara, studi pustaka, serta dokumentasi. Metode survei adalah metode penelitian yang tidak memberikan perlakuan apapun kepada responden, hanya mengumpulkan data menggunakan instrumen yang telah dibakukan, seperti angket, tes dan lain sebagainya (Sugiyono, 2016.) 


\section{HASIL DAN PEMBAHASAN}

\section{Analisis Data Persepsi dan Sikap Siswa terhadap Ekosistem Mangrove dalam Mendukung Eduekowisata}

Persepsi dan sikap siswa terhadap ekosistem mangrove dalam mendukung eduekowisatadiperoleh dari angket yang terdiri dari 18 item pertanyaan dengan 4 alternatif jawaban yaitu: Sangat Setuju (SS), Setuju (S), Kurang Setuju (KS), Sangat Tidak Setuju (STS), dengan skor masing-masing nilai yang bergerak untuk pernyataan item positif (+) adalah dari sangat setuju mendapat nilai empat sampai sangat tidak setuju mendapat nilai satu. Sedangkan untuk pernyataan negatif (-) adalah dari sangat setuju mendapat nilai satu sampai sangat tidak setuju mendapat nilai empat. Angket yang diberikan kepada responden berisikan item-item pernyataan yang disusun berdasarkan indikator. Setiap indikator dihitung persentasenya dari setiap item pernyataan yang telah diisi oleh responden. Hasil yang didapatkan dari perhitungan setiap penyataan positif dan negatif berdasarkan setiap sub indikator kemudian dihitung rata-rata persentase nya dan diinterpretasikan dengan 4 kategori.

Jadi untuk lebih jelas dapat dilihat pada rekapitulasi indikator persepsi dan sikap siswa terhadap ekosistem mangrove dalam mendukung eduekowisata. Untuk lebih jelas rekapitulasi seluruh indikator yang mempengaruhi persepsi dan sikap siswa dapat dilihat pada tabel 1 dan 2 .

\section{Persepsi Siswa}

Tabel 1. Rekapitulasi Indikator Persepsi siswa terhadap ekosistem mangrove dalam mendukung eduekowisata.

\begin{tabular}{ll}
\multicolumn{1}{c}{ Indikator Persepsi } & Keterangan (\%) Persepsi \\
\hline Fungsi Hutan Mangrove (Fisik) & 77,94 \\
\hline Fungsi Hutan Mangrove (Biologi) & 80,15 \\
\hline Fungsi Hutan Mangrove (Ekonomi) & 83,24 \\
\hline Fungsi Hutan Mangrove (Eduekowisata) & 81,74 \\
\hline Rata-rata & 80,77 \\
\hline Kategori & Sedang \\
\hline
\end{tabular}

Untuk lebih jelasnya dapat dilihat pada gambar 1 dibawah ini: 


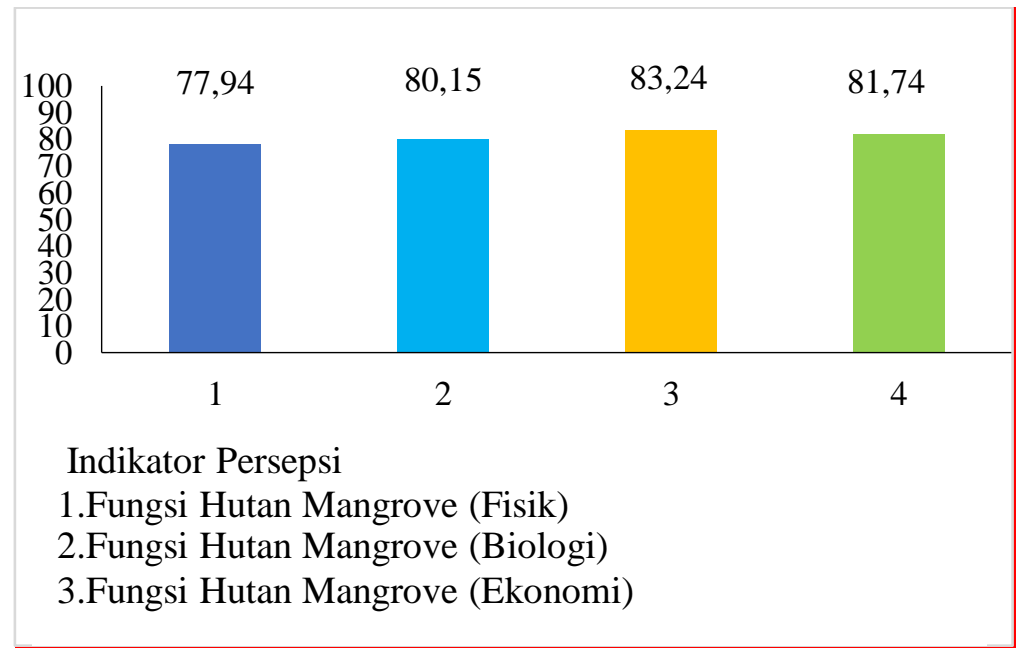

\section{Gambar 1. Persepsi peserta didik}

\section{a. Fungsi Hutan Mangrove Secara Fisik}

Hasil angketpersepsi siswa diperoleh pada indikator fungsi hutan mangrove (fisik), berhasil didapatkan rata-rata dengan persentase sebesar 77,94\% dengan kategori sedang.Berdasarkan hasil angket persepsi siswa pada indikator pertama menunjukkan bahwa siswa rata-rata sangat setuju dengan skor jawaban 29 pada item 1 dan 3. Hal ini menunjukkan bahwa siswa di Sungai Apit memiliki persepsi diri yang tinggi walaupun dalam skala indikator dalam tingkat sedang. (Maulana dan Gumelar dalam Surayya, 2017) menyatakan bahwa proses persepsi merupakan suatu proseskognitif yang dipengaruhi oleh pengalaman, cakrawala dan pengetahuanindividu.

Sementara itu secara garis besar, mangrove mempunyai beberapa keterkaitan dalam kebutuhan manusia sebagai penyedia bahan pangan, papan, dan kesehatan sehingga lingkungan dibedakan menjadi lima yaitu: Fungsi fisik, fungsi kimia, fungsi biologi, fungsi ekonomi, dan fungsi lain (Dixon, 2001 dalam Majid, dkk, 2016). Berdasarkan penelitian yang dilakukan oleh (Kustanti, 2011 dalam Karimah, 2017) menyatakan bahwa Fungsi ekologis ekosistem mangrove yaitu sebagai pelindung garis pantai, mencegah intrusi air laut, sebagai habitat berbagai jenis burung, dan lain-lain.

\section{b. Fungsi Hutan Mangrove Secara Biologi}

Hasil angket persepsi siswa diperoleh pada indikator fungsi hutan mangrove (biologi), berhasil didapatkan rata-rata dengan persentase sebesar $80,15 \%$ dengan kategori sedang. Berdasarkan hasil penelitian pada angket 
persepsi dan indikator kedua menunjukkan hasil pada item 5 dan 6 sangat setuju dengan skor masing-masing item 34,33. Hal ini membuktikan bahwa siswa di Sungai Apit sadar akan fungsi mangrove secara biologi, hal dibuktikan melalui angket yang telah mereka kerjakan. Sejalan dengan (Walgito dalam Surayya 2017), juga menyatakan bahwa terjadinya persepsi merupakan tahap yang dikenal dengan nama proseskealaman atau proses fisik, merupakan proses ditangkapnya suatu stimulus oleh alat indra manusia.

Salah satu fungsi ekosistem mangrove adalah sebagai Fungsi biologi, yaitu sebagai dearah pasca larva dan yuwana jenis jenis ikan tertentu dan menjadi habitat alami berbagai jenis biota dengan produktivitas yang tinggi, serta bersarangnya burung-burung besar (Saenger, 1981 dalam Karimah, 2017)

\section{c. Fungsi Hutan Mangrove Secara Ekonomi}

Hasil angket persepsi siswa diperoleh pada indikator fungsi hutan mangrove (ekonomi), berhasil didapatkan rata-rata dengan persentase sebesar 83,24\% dengan kategori tinggi. Berdasarkan hasil penelitian pada angket persepsi dan indikator ketiga menunjukkan hasil pada item 10 dan 13 sangat setuju dengan skor masing-masing item 39 dan 36. Hal ini membuktikan bahwa siswa Sungai Apit sangat tidak setuju apabila ekosistem mangrove yan ada dirusak maupun dimanfaatkan oleh orang-orang yang tidak bertanggung jawab akan keberlangsungan ekosistem mangrove. Sejalan dengan penelitian (Maulana dan Gumelar dalam Surayya, 2017). Pengalaman, cakrawala dan pengetahuan akan mempengaruhitingkah laku dan sikap individu terhadap suatu objek tertentu.

Ekosistem mangrove memiliki peranan ekologi, sosial-ekonomi, dan sosial-budaya yang sangat penting, misalnya menjaga stabilitas pandai dari abrasi, sumber ikan, udang dan keaneragaman hayati lainnya, sumber kayu bakar dan kayu bangunan, serta memiliki fungsi konservasi, pendidikan, ekoturisme dan identitas buadaya (Setyawan, 2006 dalam Majid, 2016)

\section{d. Fungsi Hutan Mangrove Secara Eduekowisata}

Hasil angket persepsi siswa diperoleh pada indikator fungsi hutan mangrove (eduekowisata), berhasil didapatkan rata-rata dengan persentase sebesar $81,74 \%$ dengan kategori sedang. Berdasarkan hasil penelitian pada 
angket persepsi dan indikator keempat menunjukkan hasil pada item 16 dan 17 sangat setuju dengan skor masing-masing item 48 dan 41. Dari hasil penelitian menunjukan bahwa siswa Sungai Apit memahami arti dari edukasi dalam wisata mangrove dan siswa juga akan menjaga ekosistem mangrove tersebut jika sudah mengetahui manfaatnya. Sesuai dengan penelitian Nugroho (2015) prinsip ekowisata adalah meminimalkan dampak, menumbuhkan kesadaran lingkungan dan budaya, memberikan pengalaman positif pada turis (visitors) maupun penerima (host),memberikan manfaat dan pemberdayaan masyarakat lokal.

Edu-Ekowisata berbasis lingkungan juga merupakan solusi padapemahaman anak melalui pendidikan lingkungan yang diamanatkan pada Surat Keputusan Bersama Menteri LingkunganHidup dan Menteri Pendidikan NasionalNo. Kep.07/MenLH/06/2005 dan No.05/VI/KB/2005 tentang Pembinaan dan Pengembangan Pendidikan LingkunganHidup.Menurut (Cahyo, 2007 dalam Majid, dkk, 2016) ekosistem hutan mangrove yang berfungsi menjaga daratan dari gerusan ombak dan tempat hidup dan terbiaknya biota laut, kawasan hutan mangrove juga berpotensi dikembangkan daerah wisata alam.

\section{Sikap Siswa}

Tabel 2. Rekapitulasi Indikator Sikap siswa terhadap ekosistem mangrove dalam mendukung eduekowisata.

\begin{tabular}{ll}
\hline Indikator Sikap & Keterangan (\%) Sikap \\
\hline Rasa Ingin Tahu & 83,62 \\
\hline Komunikasi & 88,26 \\
\hline Peduli Lingkungan & 86,62 \\
\hline Peduli Sosial & 87,88 \\
\hline Tanggungjawab & 87,69 \\
\hline Rata-rata & 86,81 \\
\hline Kategori & Tinggi \\
\hline
\end{tabular}


Tabel 2 menunjukkan bahwa siswa di SMA Negeri 2 Apit Sungai dan SMA Negeri 3 Sungai Apit memperoleh rata-rata keseluruhan indikator pada angket persepsi sebesar 80,77\% yang masuk dalam kategori sedang, selanjutnya untuk angket sikap memperoleh rata-rata keseluruhan indikator sebesar $86,81 \%$ yang masuk dalam kategori tinggi. Sedangkan untuk indikator sikap sudah tergambar cukup jelas dari nilai rataratanya yang tinggi.

Jika dilihat dari masing-masing indikator persepsi, maka dapat tergambarkan dari persepsi (pendapat) siswa di SMA Negeri Sei Apit dan juga dari indikator tersebut sudah tercerminkan untuk mendukung eduekowisata.

Untuk lebih jelas rekapitulasi indicator persepsi dan sikap siswa dapat dilihat pada Gambar 2:

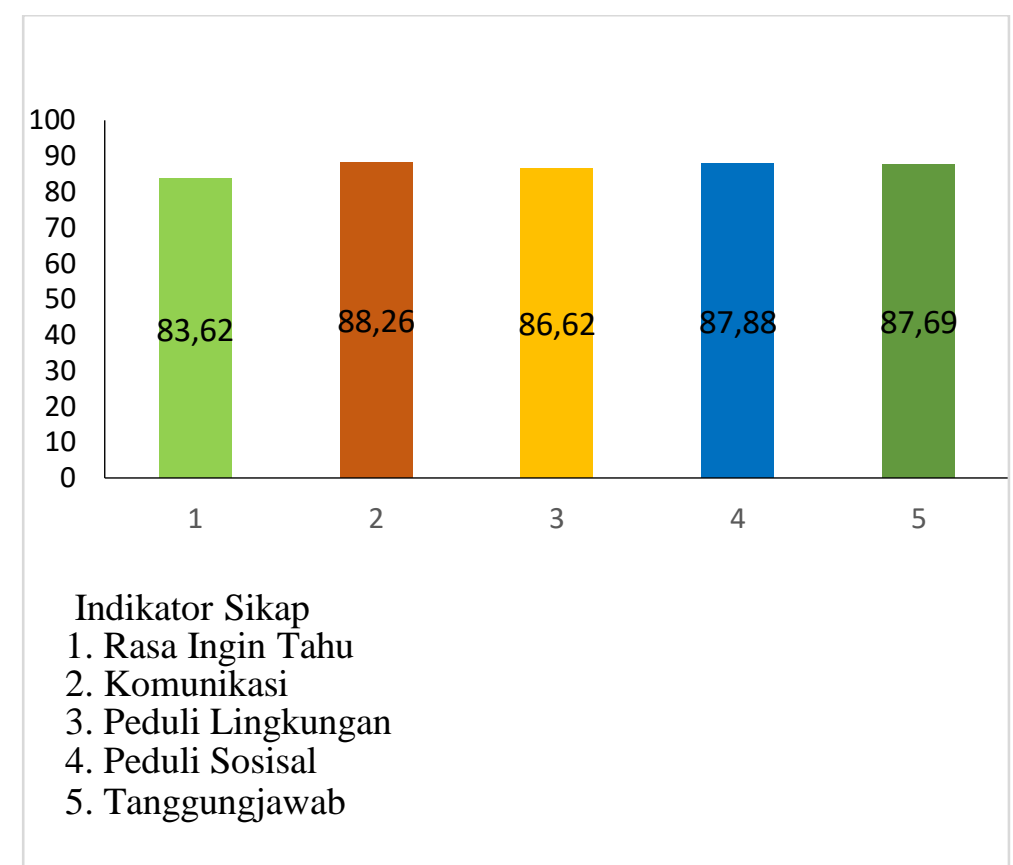

Gambar 2. Sikap Peserta didik

\section{a. Rasa Ingin Tahu}

Hasil angket persepsi siswa diperoleh pada indikator rasa ingin tahu, berhasil didapatkan rata-rata dengan persentase sebesar 83,62\% dengan kategori tinggi. Berdasarkan hasil penelitian pada angket sikap dan indikator kesatu menunjukkan hasil pada item 3 dan 4 sangat setuju dengan skor masing-masing item 32 dan 42. Dilihat dari hasil jawaban pada angket dapat disimpulkan bahwa siswa Sungai Apit memiliki sikap dan rasa ingin tahu yang tinggi walaupun ada beberapa siswa yang yang memiliki sikap acuh dengan bertambahnya umur serta 
kedewasaan siswa maka rasa ingin tahu tersebut akan tumbuh dengan sendirinya. Sesuai dengan penelitian yang dilakukan (Salirawati, 2012 dalam Silmi dan Kusmarni, 2017) keingintahuan siswa terhadap materi yang diajarkan oleh guru atau dipelajarinya sendiri dapat menyebabkan ilmunya jauh lebih banyak dibandingkan siswa yang hanya diam menunggu penjelasan dari guru.

Rasa ingin tahu adalah cara berfikir, sikap dan prilaku yang mencerminkan penesaran dan keingintahuan terhadap segala hal yang dilihat, didengar, dan dipelajari secara lebih mendalam (Kementrian Pendidikan Nasional, 2010:10 dalam Fauzi, dkk, 2017). Selanjutnya penelitian yang dilakukan oleh (Ameliah, dkk, 2016 dalam Fauzi, dkk, 2017) menyatakan bahwa dengan keingintahuan yang tinggi maka siswa akan belajar lebih, guna memenuhi kehausan akan pengetahuan yang ingin diketahui.

\section{b. Komunikasi}

Hasil angket persepsi siswa diperoleh pada indikator komunikasi, berhasil didapatkan rata-rata dengan persentase sebesar 88,26\% dengan kategori tinggi. Berdasarkan hasil penelitian pada angket persepsi dan indikator kedua menunjukkan hasil pada item 6 dan 8 sangat setuju dengan skor masing-masing item 66 dan 31. Dalam hal ini siswa dituntut agar mampu untuk berkomunikasi ataupun berunding dengan pihak lain mengenai keberlangsungan ekosistem mangrove yang ada di wilayah Sungai Apit.

Jika kita ingin mempengaruhi orang lain,maka terlebih dahulu merebutperhatiannya, kemudian membangkitkankebutuhannya, berikan petunjuk padaorang tersebut bagaimana caramemuaskan kebutuhan tersebut,kemudian berikan gambaran dalamfikirannya mengenai keuntungan dankerugian yang akan ia peroleh apabilamenerapkan atau tidak menerapkangagasan kita, pada akhirnya berilahdorongan kepadanya agar ia mau mengambil tindakan (Monroe dalam Nurhadi dan Kurniawan, 2017). Keterampilan komunikasi adalah "kemampuan seseorang untuk menyampaikan atau mengirim pesan kepada khalayak (penerim pesan)" (Changara, 2008;85 dalam Kamaruzzaman, 2016). 


\section{c. Peduli Lingkungan}

Hasil angket persepsi siswa diperoleh pada indikator peduli lingkungan, berhasil didapatkan rata-rata dengan persentase sebesar 86,62\% dengan kategori tinggi.Berdasarkan hasil penelitian pada angket persepsi dan indikator ketiga menunjukkan hasil pada item 9 dan 10 sangat setuju dengan skor masing-masing item 32 dan 42. Dari hasil angket dapat dilihat bahwasannya siswa di Sungai Apit sangat peduli akan lingkungan hal tersebut dapat disimpulkan dari hasil angket yang mereka kerjakan. Selain itu lingkungan dapat berfungsi untukmemperkaya materi pengajaran, memperjelas prinsip dan konsep yang dipelajari dalam bidang studi dan bisa dijadikan sebagai labolatorium belajar siswa (Sudjana dan Rivai, 2013:214 dalam Lestari, 2018)

Penanaman fondasi peduli lingkungan sejak dini menjadi solusi utama yang harus dilakukan, agar generasi muda memiliki bekal pemahaman tentang lingkungan hidup. Pendidikan lingkungan diharapkan mampu mendidik siswa agar berprilaku peduli terhadap lingkungan (Amini dan Munandar, 2010:15 dalam Lestari, 2018)

\section{d. Peduli Sosial}

Hasil angket persepsi siswa diperoleh pada indikator peduli sosial, berhasil didapatkan rata-rata dengan persentase sebesar 87,88\% dengan kategori tinggi.Berdasarkan hasil penelitian pada angket persepsi dan indikator keempat menunjukkan hasil pada item 13 dan 14 sangat setuju dengan skor masingmasing item 36 dan 41.Dalam hal sikap peduli sosial siswa siswa dalam hal ini terlihat mampu untuk memanfaatkan keadaan sekeliling terutama ekosistem mangrove sebagai tanggung jawab bersama antara pemerintah, masyarakat dan siswa, hal ini dapat dibuktikan dari angket yang telah dikerjakan. Sejalan dengan penelitian (Suyadi, 2013:9 dalam Setiawan, at al,) peduli sosial adalah sikap dan perbuatan mencerminkan kepedulian terhadap orang lain maupun masyarakat yang membutuhkan. Model analisis dilema sosial memiliki dampak positif terhadap sikap kepedulian sosial siswa dalam bermasyarakat (Setiawan, at al, 2017). 


\section{e. Tanggung jawab}

Hasil angket persepsi siswa diperoleh pada indikator tanggungjawab, berhasil didapatkan rata-rata dengan persentase sebesar 87,69\% dengan kategori tinggi.Berdasarkan hasil penelitian pada angket persepsi dan indikator kelimat menunjukkan hasil pada item 16 dan 17 sangat setuju dengan skor masingmasing item 40 dan 43. Pada indikator tanggungjawab terlihat siswa sangatlah bertanggung jawab terhadap kawasan ekosistem mangrove dari beberapa item tersebut sudah sangat jelas seperti terlihat pada item menanam bibit mangrove di bibir pantai yang abrasi. Sejalan dengan penelitian (Shadily dalam Rochmah, 2016). Tanggung Jawab merupakan suatu pengertian dasar untuk memahami manusiasebagai makhluksusila, dan tinggi rendahnya akhlak yang dimilikinya.

Rasa tanggung jawab kemudian berkembang bukan hanya pada tataran personal, namun selalu dikaitkan dengan hubungan dengan orang lain, sehingga dapat dibuat dalam sistem hukum, bahkan hukum pidana. Seseorang yang terhubung dengan pihak-pihak lain tidak bisa lepas dari rasa tanggung jawab yang melekat pada dirinya (Aunillah dalam Rochmah, 2016). Tanggung jawab adalah sikap dan perilaku seseorang untuk melaksanakan tugas dan kewajibannya, yang seharusnya dilakukan, terhadap diri sendiri, masyarakat, lingkungan (alam, sosial dan budaya), negara dan Tuhan Yang Maha Esa (Hasan, 2010:10 dalam Rahayu 2016).

\section{KESIMPULAN DAN SARAN}

Berdasarkan hasil pengolahan data dan analisis data penelitian yang telah diuraikan, dapat disimpulkan bahwa persepsi dan sikap peserta didik terhadap kawasan ekosistem mangrove dalam mendukung eduekowisata di kecamatan sungai apit masuk dalam kategori tinggi.

Berdasarkan hasil penelitian yang diperoleh ada beberapa saran yang dapat peneliti berikan, yaitu:

1) Bagi guru bidang studi IPA di SMA Negeri 2 Sungai Apit dan SMA Negeri 3 Sungai Apit, hendaknya dapat memberikan penguatan dan pengarahan berupa motivasi kepada siswa agar dapat peduli lingkungan serta bahkan dapat dilakukan dengan metode secara outdoor learning. 
2) Bagi siswa, janganlah berpangku tangan menunggu perintah dari guru untuk belajar, timbulkanlah rasa ingin tahu yang tinggi dalam diri sendiri terhadap sesuatu, terutama yang terjadi kawasan ekosistem mangrove.

3) Bagi peneliti selanjutnya, sebaiknya memperluas kajian yang diteliti yakni bukan hanya aspek persepsi dan sikap tetapi bisa dalam bentuk pengembangan buku ajar mengenai ekosistem mangrove.

\section{DAFTAR PUSTAKA}

Q. Surayya, "Persepsi Siswa Terhadap Fungsi Hutan Mangrove Karangsong Sebagai Sumber Belajar Geografi (Studi Kasus Siswa Kelas XI SMAN 2 Indramayu),” 2017.

I. Majid, M. H. I. Al Muhdar, F. Rohman, and I. Syamsuri, "Konservasi Hutan Mangrove Di Pesisir Pantai Kota Ternate Terintegrasi Dengan Kurikulum Sekolah," Bioedukasi Univ. Khairun, vol. 4, no. 2, 2016.

Karimah, "Peran Ekosistem Hutan Mangrove Sebagai Habitat Untuk Organisme Laut," J. Biol. Trop., vol. 17, no. 2, pp. 51-58, 2017.

M. Silmi and Y. Kusmarni, "Menumbuhkan Karakter Rasa Ingin Tahu Siswa Dalam Pembelajaran Sejarah Melalui Media Puzzle," FACTUM J. Sej. dan Pendidik. Sej., vol. 6, no. 2, pp. 230-242, 2017, doi: 10.17509/factum.v6i2.9980.

A. R. Fauzi, Z. Zainuddin, and R. Al Atok, "Penguatan Karakter Rasa Ingin Tahu dan Peduli Sosial melalui Discovery Learning," J. Teor. dan Praksis Pembelajaran IPS, vol. 2, no. 2, pp. 79-88, 2017, doi: 10.17977/um022v2i22017p079.

Effendy OU, “Dinamika Komunikasi,” no. 1, pp. 90-95, 2008.

K. Kamaruzzaman, "Analisis Keterampilan Komunikasi Interpersonal Siswa," J. Konseling Gusjigang, vol. 2, no. 2, pp. 202-210, 2016, doi: 10.24176/jkg.v2i2.744.

Y. Lestari, "Penanaman nilai peduli lingkungan dalam pembelajaran ilmu pengetahuan alam," J. Pendidik. Ke-SD-an, vol. 4, no. 2, pp. 332-337, 2018, doi: http://dx.doi.org/10.30738/trihayu.v4i2.2238.g1502.

M. A. Setiawan, R. Vien, and H. Suryono, "Penerapan Model Analisis Dilema Moral Terhadap Sikap Peduli Sosial Siswa Pada Kompetensi Dasar Menampilkan Sikap Positif Berpancasila Dalam Kehidupan Bermasyarakat,” Paedagogia, vol. 20, no. 
1, p. 88, 2017, doi: 10.20961/paedagogia.v20i1.16602.

A. L. Murabbi, “6-Mengembangkan Karakter Tanggungjawab Pada Pembelajar,” vol. 3, pp. 36-54, 2016.

R. Rahayu, "Peningkatan Karakter Tanggung Jawab Siswa SD," Psychol. Appl. to Work An Introd. to Ind. Organ. Psychol. Tenth Ed. Paul, vol. 53, no. 9, pp. 1689-1699, 2016, doi: 10.1017/CBO9781107415324.004.

Abdah Fajar, (2016). Departemen konservasi sumber daya hutan dan ekosistem. Persepsi masyarakat terhadap hutan mangrove di desa margasari kabupaten lampung timur. 8. 3-5.

Listyana Rohman, (2015). Jurnal Agastya. Persepsi dan Sikap Masyarakat Terhadap Penggalan Jawa dan Penentuan Waktu Pernikahan (Studi kasus desa Jonggrang Kecamatan Barat Kabupaten Magetan). 5. 121-122.

Prianto Eko, (2006). Jurnal Biodiversitas. Keanekaragaman hayati dan struktur ekosistem mangrove dewasa dikawasan pesisir kota dumai Provisni Riau. 7. 327. Sugiyono, (2016). Metode Penelitian Kuantitatif, Kualitatif, dan R\&D. Bandung: Alfabeta. 